\title{
ENIGMA EM TIZANGARA: \\ O FANTÁSTICO EM O ÚLTIMO VOO DO FLAMINGO, DE MIA COUTO
}

OLIVEIRA, Ana Maria Abrahão dos Santos

\section{Introdução}

Utilizando uma linguagem que se aproxima do fantástico e fazendo uma literatura de cunho engajado histórica e socialmente, o moçambicano Mia Couto representa em O último voo do flamingo $(2000)^{1}$, a dor, a miséria e as consequências traumáticas da guerra civil ou Guerra dos dezesseis anos que se seguiu a anticolonial. Em suas narrativas, sempre há um mapeamento dos obstáculos a serem enfrentados no processo de construção do país, levando em conta que existe um conflito peculiar à multifacetada herança colonial, assim como o confronto entre os valores modernos e os dos antepassados.

A presença de elementos que se aproximam do fantástico, que na ficção de Mia Couto atuam como fortes expressões das tradições acentuam também uma marcante resistência à opressão sofrida pela população moçambicana, cujo país é um dos mais pobres do mundo. Para isso, o escritor parte do discurso literário em Língua Portuguesa, em que se mesclam a linguagem coloquial e a cultura nativa. Evita tratar os problemas sociais de seu país de modo panfletário, prefere utilizar o lirismo narrativo que o fazer literário lhe concede para representar seus personagens, com enredos em que a ironia, a tradição e os questionamentos são a tônica.

Segundo Enilce A. Rocha (2006), a colonização portuguesa, tal como as demais européias, com o fito de defender seus interesses econômicos e para impor sua ideologia e sua cultura, fizeram tudo para minar a pluralidade cultural a fim de "impedir a construção de qualquer manifestação nacional e tornar possível a simples idéia ou sonho de uma nação moçambicana (...) [tornando desse modo] as culturas africanas (...) inferiorizadas, negadas (...)" (ROCHA: 2006, p. 46)

${ }^{2}$ Ano da primeira edição da obra em Portugal. 


\section{Medo e perplexidade em Tizangara}

Em O último voo do flamingo, o leitor é direcionado a um lugar fictício, a vila de Tizangara, envolvido por uma atmosfera de mistério e de medo. $\mathrm{Na}$ primeira cena do romance, deparamo-nos com um fato que suscita o riso e, ao mesmo tempo, apresenta-se como insólito. Corpos de soldados das forças de paz explodem misteriosamente e os habitantes da vila encontram "pedaços" de cadáveres e o mais inusitado: um pênis decepado. Ironicamente todos querem descobrir quem é o "dono" daquele sexo separado ou avulso. "Em Tizangara, só os fatos são sobrenaturais" (COUTO: 2008, p. 15)

Ana Deusqueira, uma das prostitutas da cidade, é convocada para reconhecer de quem era aquele sexo decepado pois " ela era (...) a mais competente conhecedora de machos locais."2 (p.26)

A narrativa, por meio de ironia e da exposição de uma situação ridícula, desperta o leitor para a desfaçatez reinante naquele lugar: uma sociedade onde imperam a corrupção e a desigualdade. As autoridades são representadas como figuras burlescas e autoritárias, em especial, o administrador Estevão Jonas _ personagem que também aparece em Terra sonâmbula (1992), primeiro romance do autor _ e sua esposa Ermelinda, a "administratriz", mulher arrogante e orgulhosa que vive a exibir-se com suas jóias de ouro, diante da miséria do povo do lugar.

Quando voltara da guerra anti-colonial, Estêvão Jonas era visto como um deus. Proclamara que o país seria grande com a independência. Entretanto, ao assumir o poder em Tizangara, “(...) Estevão Jonas deixara de sonhar em grandes futuros. Morrera o quê dentro dele? (...) sua vida esqueceu-se de sua palavra. O hoje comeu o ontem." ( p. 161)

O italiano Massimo Risi, um oficial das Nações Unidas, é enviado para solucionar o mistério das explosões dos soldados, de quem só restaram os órgãos sexuais. Ana Deusqueira, numa atitude que nos remete às prostitutas da ficção de Jorge Amado (influência confessa de Mia Couto, que admira profundamente a Literatura Brasileira), _ lembremos aqui a personagem Teresa Batista e outras meretrizes que ajudaram a população de uma cidade,

\footnotetext{
${ }^{2}$ A partir dessa citação, só indicaremos o número da página do romance, visto que utilizamos a seguinte edição, COUTO, Mia. O último vôo do flamingo, São Paulo: Cia. das Letras, 2008.
} 
acometida por uma epidemia de varíola, fazendo assim o papel das autoridades sanitárias do lugar, que se omitiram com receio do contágio, o que sinaliza a consciência social dessas prostitutas e sua preocupação com os problemas do povo _ mostra indignação e revolta com o descaso da ONU e das autoridades presentes, perante a população de Moçambique. "Morreram milhares de moçambicanos, nunca vos vimos cá. Agora desaparecem cinco estrangeiros e já é o fim do mundo?" (p. 32)

Através da fala da prostituta, a narrativa faz uma crítica contumaz à desconsideração que sofre o povo moçambicano pelos órgãos internacionais, como a ONU. A história é narrada pelo tradutor nomeado pelas autoridades de Tizangara para acompanhar o enviado das Nações Unidas. Este tradutor é um narrador-observador na narrativa e seu nome não é mencionado em nenhum momento. A missão principal de Massimo Risi não é apenas desvendar o mistério dos homens que explodiram, mas também e principalmente, revelar um enigma maior: a cultura moçambicana. Por isso, o trabalho do tradutor é fundamental para a permanência de Risi em Tizangara, pois poderá dar pistas ao italiano que possam facilitar a compreensão de valores tão diversos dos ocidentais. O italiano fala português, mas como estrangeiro é tomado pelo estranhamento diante de fatos tão insólitos que ocorrem naquela vila. "Eu posso falar e entender. Problema não é a língua. O que eu não entendo é esse mundo daqui." (p. 40) E mais adiante: "Sentiu-se só, com toda aquela África lhe pesando" (p. 100)

\section{O fantástico em $O$ último voo do flamingo}

Para Bela Josef (2006), as representações da visão realista e da descrição objetiva do mundo declinam na literatura contemporânea. Há um afastamento da representação direta da realidade, direcionando-se a ficção para a criação de um mundo mágico e simbólico, uma metáfora do mundo real. "Cria-se um cenário de dimensões transcendentais, explorando o reino do subjetivo e do maravilhoso." (JOSEF: 2006, p. 181)

O fantástico em O último vôo do flamingo possui uma conotação política, visto que é utilizado não só a fim de perenizar as tradições, mas, principalmente, para denunciar a situação de Moçambique e de todo o continente africano em relação ao resto do mundo. 
O realismo fantástico se faz presente em várias páginas do romance. Inicialmente, na abertura da narrativa. "Seis soldados das Nações Unidas tinham-se eclipsado, (...) Como podiam soldados estrangeiros dissolver-se assim, despoeirados no meio das Áfricas, que é como se diz, no meio do nada?" (p. 30) De acordo com a fala de Zeca Andorinho, o feiticeiro, a "explicação" para as explosões dos soldados seria o uso de feitiços denominados "likaho". "Fazia esse feitiço por encomenda dos homens de Tizangara. Ciúme dos locais contra os visitantes. Inveja de suas riquezas, ostentadas só para fazer suas esposas tontearem. (...) castigo contra os olhares dos machos estrangeiros. “ (p. 146) Andorinho utilizava esse feitiço contra os "gafanhotos", ou seja, os homens de capacete azul, os soldados da ONU.

A crítica mordaz ao governo de Moçambique e às Nações Unidas tem como seu principal fulcro a figura de Estêvão Jonas. No romance, esse personagem havia sido um guerrilheiro revolucionário da FRELIMO (Frente para a Libertação de Moçambique) que lutava com a população pela independência do país. Porém, quando Moçambique livrou-se das amarras do colonizador, e Estevão assumiu a administração, só agiu em benefício próprio, enriquecendo rapidamente e deixando o povo à margem, na miséria. Essa parece ter sido a postura assumida pela FRELIMO, da qual o próprio Mia Couto fazia parte e a quem dirige abertamente suas críticas em seus romances e nas entrevistas que concede.

Retomando a questão do fantástico, de acordo com Todorov (2004), esse gênero envolve não somente a ocorrência de um fato estranho à realidade concreta, que suscita a hesitação do leitor e do herói; mas também num modo de percepção do mundo. A nosso ver, o romance de Mia Couto enquadra-se no fantástico-maravilhoso, termo cunhado pelo teórico francês de origem búlgara. "O fantástico-maravilhoso [está] na classe das narrativas que se apresentam como fantásticas e que terminam por uma aceitação do sobrenatural (...) sugere-nos realmente a existência do sobrenatural" (TODOROV: 2004, p. 58)

Além do episódio dos soldados que explodem, há outros que merecem destaque, como Temporina, a "mulher escamosa", que apresenta o rosto de 
uma mulher idosa (pois fora castigada pelos espíritos) e o corpo de uma jovem sensual, cuja idade era indefinida. “(..) corpo (...) de moça polpuda e convidativa. (...) Pode uma velha com tamanha idade inspirar desejos num homem (...)?" (p.39)

A presença dessa mulher estranha, jovem e velha, não causa espanto aos habitantes de Tizangara, que a veem de modo natural, assim como encaram os outros fatos insólitos que acontecem no lugar como algo que faz parte de seu cotidiano. Apenas o italiano espanta-se com o que vê. "_Ah, essa é Temporina. Ela só anda no corredor, vive no escuro, desde há séculos. “ (p.39)

Ainda referindo-nos à "mulher escamosa", atentemos também para a sua tia Hortênsia. Já havia falecido, mas visitava a sobrinha e para isso, tomava a forma de um inseto. "Hortênsia, a falecida, (...) visitava a pensão em forma de louva-a-deus (...) iria visitar os vivos em outras formas." (p. 62)

Isso posto, importa mencionar a relação dos vivos com os mortos no romance. É como se não houvesse uma fronteira entre o mundo dos vivos e o dos mortos. Estes "convivem" com os vivos, o que faz parte da crença dos moçambicanos. O tradutor de Massimo Risi também reencontra a mãe. "Me virei: era minha mãe. (...) há muito passara a fronteira da vida, para além do nunca mais, (...) ela surgia nas folhagens, envolta em seus panos escuros, seus habituais." (p. 111)

A presença do elemento fantástico dá-se também com o pai do tradutor, o velho Sulplício, cujo nome já é um indicativo de todo o sofrimento pelo qual ele e também toda a população moçambicana passaram durante as duas guerras. Sulplício possuía uma singularidade. Já falara com o filho sobre o assunto, mas este não acreditara. Pôde crer apenas depois que presenciou a transformação do pai.

(...) eu o segui espiando, a espreitar a verdade de sua fantasia de pendurar o esqueleto. Foi então que, por trás dos arbustos, me surpreendeu a visão de arrepiar a alma: meu pai retirava do corpo os ossos e os pendurava nos rumos de uma árvore. (...) já desprovido de interna moldura, ele amoleceu, insubstanciando-se no meio do chão. Ficou ali esperamorto, igual uma massa suspirosa (...) só os ossos da maxilas ele conservava. Para as falas, conforme (...) explicou. (p. 211) 


\section{O flamingo, ícone da esperança.}

A história dos flamingos surge nesse cenário pós-guerra como um ícone de esperança. Certa vez o flamingo disse: "_ Hoje farei meu último voo!" (p. 113) Reuniu-se com os outros em assembleia e afirmou que havia dois céus e que queria ultrapassar o limite entre os dois. "Queria ir lá onde não há sombra, nem mapa. Lá onde tudo é luz (...) Mais um bater de plumas e, de repente, a todos pareceu que o horizonte se vermelhava (...) Nascia assim o primeiro poente. Quando o flamingo se extinguiu, a noite se estreou naquela terra" ( $p p$. 114-115)

Para os pescadores, os flamingos eram os "salva-vidas". Quando estavam perdidos em alto-mar, eram os sons emitidos pelos flamingos que thes orientava a direção a seguir. "Se confirmava, na vertência do caso, a vocação salvadora dos pássaros" (pp. 132-133)

Até mesmo o italiano Massimo Risi deixa-se enredar pelas trilhas da crença e da tradição africanas, em suas últimas palavras, no capítulo final, num diálogo com o seu tradutor. (Tradutor) "_ Que vamos fazer? (...) (Massimo) _ Esperar por outro voo do flamingo. Há-de vir um outro" (p. 220)

No desfecho da narrativa, os deuses fazem o país desaparecer numa imensa cratera, pois os governantes não o amavam o suficiente, fazendo a população sofrer com a penúria, com a miséria e a corrupção.

(...) a nação desaparecera naquela infinita cratera. (...) Era esse o triste julgamento dos mortos sobre o estado dos vivos. Já acontecera com outras terras de África. Entregara-se o destino dessas nações a ambiciosos que governavam como hienas, pensando apenas em engordar rápido. (...) Faltava gente que amasse a terra. (...) Nesse lugar onde nunca nada fizera sombra, cada país ficaria em suspenso, a espera de um tempo favorável para regressar ao seu próprio chão. (p. 216)

\section{Considerações finais}

A narrativa de Mia Couto traz à tona um olhar questionador sobre a realidade de seu país, além de impregnar as páginas de $O$ último voo do flamingo de um caráter mágico, aproximando sua ficção do realismo fantástico, ou do fantástico-maravilhoso, segundo a terminologia de Todorov. ${ }^{3} \mathrm{O}$ escritor

3 Op. Cit. 
moçambicano conduz para o universo da representação os contrates entre dois mundos: o de Moçambique, país jovem do continente africano, ex-colônia de Portugal, e que sofre até hoje as marcas indeléveis das guerras pelas quais passou, aqui representado pelos habitantes da Vila de Tizangara; e de outro lado, o mundo europeu, elitizado, colonizador de vários países, aqui personificado pelo estrangeiro Massimo Risi,

(...) pois na realidade todo movimento de aproximação do Ocidente com a África tem sido mediado pela violência e no sentido da diluição de suas referências. $\mathrm{Na}$ forma de exploração desenfreada ou sob a máscara da cooperação, o continente (...) continua sendo vítima de políticas e acordos que só vêm afastando da situação de paz necessária a sua recuperação. (CHAVES: 2005, p. 247)

As páginas do autor moçambicano mostram-nos que aqueles que se empenharam para tornar Moçambique um país livre, tornaram-se depois, inimigos do povo. Mais uma vez, as palavras da prostituta Ana Deusqueira fazem emergir a dura realidade enfrentada pela população:

A desgraça é esta: só uns poucos aprenderam a lição da humanidade (...) Estes poderosos de Tizangara têm medo de suas próprias pequenidades. Estão cercados, em seu desejo de serem ricos. Porque o povo não Ihes perdoa o facto de eles não repartirem riquezas. A moral aqui é assim: enriquece sim, mas nunca sozinho. São perseguidos pelos pobres de dentro, desrespeitados pelos ricos de fora. (pp. 178-179)

Ficção que utiliza em sua tessitura elementos do fantástico para preservar as tradições e em especial, como forma de resistência à toda imposição social, econômica e cultural sofrida pelos moçambicanos, não envereda pelos caminhos da panfletagem, mas sim, por uma veia mítica e pelas sendas da tradição oral, representando aqueles que "ainda 'ousam' ter esperança, não obstante estarem imersos em situações de barbárie, arbitrariedades e abuso de poder, [trazendo] uma escrita que potencializa o valor dos sonhos e o seu talento para converter e regenerar a vida (...)" (OLIVEIRA: 2008, p. 89) 
Encerramos nossa reflexão com as palavras do escritor ${ }^{4}$ que crê firmemente na reconstrução de seu país e com os dizeres de Zeca Andorinho, o feiticeiro de Tizangara, respectivamente.

A terra, a árvore, o céu: é na margem desses dois mundos que tento a ilusão de uma costura. É uma escrita que aspira ganhar sotaques do chão, fazer-se seiva vegetal (...) sonhar o voo da asa rubra. É uma resposta pouca perante os fazedores de guerra e construtores da miséria. Mas é aquela que sei e que posso (...) (pp. 224-225)

O que fizeram esses brancos foi ocuparem-nos. Não foi só a terra: ocuparam-nos a nós, acamparam no maio de nossas cabeças. Somos madeira que apanhou chuva. Agora não acendemos nem damos sombra. Temos que secar à luz de um sol que ainda não há. Esse sol só pode nascer dentro de nós. (p.154)

\section{Referências Bibliográficas}

CHAVES, Rita. Angola e Moçambique: Experiência Colonial e Territórios Literários. São Paulo: Ateliê Editorial, 2005.

COUTO, Mia. O último voo do flamingo. São Paulo: Companhia das Letras, 2008.

JOSEF, Bela. O fantástico e o misterioso. In: JOSEF, Bella. A máscara e o enigma. Rio de Janeiro: Livraria Francisco Alves Editora S. A; Eduel, 2006, pp. 180-190.

OLIVEIRA, Ana Maria Abrahão S. Ensinar a sonhar: o insólito nas páginas fantásticas de Terra sonâmbula, de Mia Couto. In: Anais das comunicações livres do IV Painel "Reflexões sobre o Insólito na narrativa ficcional": Tensões entre o sólito e o insólito. Rio de Janeiro: UERJ, 2008. Disponível em www.dialogarts.uerj.br/avulsos/comunicacoes_livres_IV_painel.pdf.

ROCHA, Enilce Albergaria. A narrativa ficcional e a identidade cultural: a guerra pós-independência em Moçambique na escrita de Mia Couto. In: Vozes (além) da África. Inacio G. Delgado [et al.]. Juiz de Fora: Editora UFJF, 2006.

TODOROV, Tzvetan. Introdução à literatura fantástica. Tradução: Maria Clara Correa Castello. 3a edição, São Paulo: Perspectiva, 2004.

\footnotetext{
${ }^{4}$ Mia Couto proferiu estas palavras por ocasião da entrega do Prémio Mário Antônio, da Fundação Calouste Gulbenkian, em 2001. Este discurso vem anexado ao livro O último voo do flamingo, no Brasil, na edição utilizada por nós.
} 


\title{
UMA LEITURA DE CONTOS DE JOSÉ MARÍA ARGUEDAS SOB O SIGNO DA TRANSCULTURAÇÃO
}

\author{
SÁ, Luiz Fernando Ferreira ${ }^{1}$
}

Inicio o presente artigo citando Arguedas: "La novela, el cuento y la poesía mostraban um indio sustancialmente distinto del verdadero y no solo al indio sino todo el universo humano y geográfico de los Andes." (1957, p. 33) Em outro momento, Arguedas repete a sua posição de maneira categórica:

\begin{abstract}
Yo comencé a escribir cuando leí las primeras narraciones sobre los indios; los describían de una forma tan falsa escritores a quienes yo respeto, de quienes he recibido lecciones como López Albújar, como Ventura García Calderón. López Albújar conocía a los indios desde su despacho de Juez en asuntos penales y el señor Ventura García Calderón no sé cómo había oído hablar de ellos ... En esos relatos estaba tan desfigurado el indio y tan meloso y tonto el paisaje o tan extraño que dije: 'No yo lo tengo que escribir tal cual es, porque yo lo he gozado, y yo lo he sufrido' y escribí esos primeros relatos que se publicaron en el pequeño libro que se llama Agua. (1969, p. 40-41)
\end{abstract}

Mostrar a verdade Andina e corrigir a forma como os escritores representaram um índio desfigurado são declarações de boa intenção como nos alerta Mario Vargas Llosa em seu artigo "Jose Maria Arguedas, Entre Sapos e Halcones". Llosa continua: "sua obra [a obra arguediana], na medida em que é literatura, constitui uma negação radical do mundo que a inspira: una hermosa mentira". (1978, p. 93) No caso de Arguedas, parece-nos, sua visão de mundo e sua mentira foram muito persuasivas e se impuseram como verdade artística; ao mesmo tempo aquém e além da literatura.

Em artigo de 2001 intitulado, "Os processos de transculturação na narrativa latino-americana", Ángel Rama destaca a capacidade elástica que a literatura teria de incorporar diferentes línguas, visões de mundo e objetos. Voltando a Rama, Marcos Natali (2005), em artigo intitulado "José María

\footnotetext{
1 Professor Adjunto de Literaturas de Expressão Inglesa e Literatura Comparada na FALE/UFMG. Texto apresentado, de forma resumida, no Coloquio Internacional: A herança de Arguedas aos 40 anos de sua ausência, em junho de 2010, na FALE/UFMG.
} 
Arguedas aquém da literatura", lista o que ele pensa ser os elementos básicos da escrita arguediana:

Se não faltam vozes dispostas a fazer a tradução de diferentes práticas discursivas a uma definição universalista de literatura, inclusive em nome dos subalternos, a voz solitária de Arguedas parece insistir no direito a não fazer literatura, no direito a não ser imediatamente reduzido à ficção, no direito a não ter que escolher entre fato e fetiche, literatura e história. (p. 127)

$\mathrm{Na}$ linha do pensamento de Rama e de Natali sobre a ficção de Arguedas, o presente artigo passará em revista os seguintes contos: "El Barranco", "Orovilda", "La Muerte de Los Arancos", "Hijo Solo", "El Forastero" e "Agua."

Comecemos, então, a considerar as modificações profundas da realidade e os desacatos subjetivos que Arguedas engendrou em relação a seu mundo no conto "Agua" (1958). O narrador desse conto é o menino Ernesto, um personagem que nos remete a uma agonística integração entre índios e brancos ou entre uma visão de mundo ingênua negociando com as necessidades e costumes dos trabalhadores rurais andinos. $\mathrm{O}$ conto trata da divisão das águas de uma lagoa pertencente à comunidade de San Juan e do rancho Ventanilla. Braulio Félix, administrador regional ou "varayok" da região de San Juan, é o encarregado de supervisionar tal operação. Os índios, por um lado, temem o poder de Braulio, mas são incitados à luta pelo músico Pantaléon. Pantaléon morre ao enfrentar Braulio, e Ernesto, o narrador menino, ataca Braulio com uma corneta matando-o. O cacique da tribo ordena a morte de Ernesto, mas o menino foge e refugia-se na comunidade de Utek Pampa, comunidade de índios livres e proprietários de terra que vive de acordo com suas próprias leis.

Mas o que há de transculturação na narrativa acima? Podemos responder a pergunta com a ajuda de Marcos Natali (2005): a transculturação literária tem a ver com a construção de pontes indispensáveis para o resgate de culturas regionais, serve para a busca de soluções artísticas que não sejam contraditórias com a herança que devem transmitir, restaura a visão regional e instaura-a, de forma bem-sucedida, no sistema global. No conto "Agua", a ponte indispensável para o resgate ou manutenção da cultura indígena local encontra-se na descrição de comunidades indígenas submissas, no relato da 
prepotência branca ou "misti", na narrativa de desacordo e na posterior fuga do menino narrador em direção a uma comunidade indígena independente. A rebelião, por assim dizer, transmite uma herança ou possui um substrato ecológico, qual seja: o elemento líquido ou água da lagoa não se vende, pois o respeito e uso racional, ou comunal, da natureza, devem prevalecer.

Outro exemplo de transculturação ou hibridismo cultural na obra de Arguedas emerge no conto "El Forastero" (1972). O foco do enredo aí se resume a um homem sem nome que chega a uma estação de uma cidade guatemalteca sem destino/desígnio preciso e se depara com os signos de identidade (o que extamente na estação se daria a ver como especificidade do povo que habita aquele local) e simultaneamente, com os signos de outridade (o que exatamente na estação se daria a ver como diferença a partir da visão do forasteiro). As semelhanças e as diferenças são narradas no mesmo espaço onde viventes excluídos habitam: "Percibió la gran semejanza de esos hombres recostados en el suelo, con los pies desnudos, y la musical estación de su pueblo lejanísimo, donde muchos dormían en iguales posturas, mientras (otros) tocaban quenas y charangos". (ARGUEDAS: 1972, p. 79-80) O sentimento de pertencimento aí se dá por meio da constatação de que o forasteiro do conto e o povo local são seres excluídos ou subalternos na sociedade guatemalteca, ao mesmo tempo em que são estrangeiros ou seres diferentes na sua condição de indígenas peruanos.

A viagem narrativa desse conto ocorre quando narrador e leitor descobrem que o pertencimento será escrito como não-pertencimento e que a suposta identidade se constituirá via alteridade (de início, feminina): “--!Estás 'bolo', papacito! !Más que yo!" E María vê nele uma forma de alteridade: “--?No sabes? No pareces mexicano, ni panameño, ni de Nicaragua... A esos los conozco en seguida. ¿De dónde? -Soy del Perú." (ARGUEDAS: 1972, p. 80) Daí em diante o forasteiro acompanha a prostituta de (codi)nome María em visita a seu filho. A essa família "bastarda" se juntam outros componentes de alteridade e hibridização: uma mulher indígena guatemalteca (prostituta separada de seu filho em razão de seu trabalho e separada da cultura indígena em razão da cultura "global" que lá se instala); o filho indígena guatemalteco (menino inocente, separado de sua mãe); um homem indígena peruano 
(separado de sua terra e de sua vida autóctone pela cultura "criolla"); um velho negro afroamericano (separado de sua origem e também de sua vida autóctone pelos condicionamentos históricos e pelo homem branco).

O conto termina em chave poética e com uma pergunta retórica impossível de ser respondida, senão simbolicamente e apontando (como um índice) em direção a outra estranheza ou alteridade: "-- ? De dónde me dijo que era? Sólo recordaba un nombre, como indicio; la extraña palavra cóndor." (ARGUEDAS: 1972, p. 89) Há, aí, uma tensão telúrica entre o forasteiro e o seu espaço de vivência, entre a possibilidade de vivência autóctone ou social e o seu local de cultura, entre sujeito híbrido e concepção mística, eco-lógica, desse mundo desterritorializado. Em suma, "El Forastero" se inscreve no contexto de migração e se insinua (de forma autobiográfica?) na obra de José María Arguedas não como um texto/sujeito aculturado, mas sim como um texto/sujeito transculturado.

É nesse processo quando culturas se chocam como resultado da presença do migrante, do sujeito híbrido ou desterritorializado, que se abrem portas para a transculturação; o espaço recuperado é também a história recuperada. Como nos adverte Fernando Ortiz (1983), pesquisador cubano, devemos estar atentos ao processo transitivo das culturas. Ortiz nos ensina que "transculturação" não definiria apenas o ato de adquirir uma cultura como era subentendido pelo termo "aculturação", senão que, além da perda ("desaculturação"), poderia haver a criação de uma nova cultura, o que seria denominado "neoculturação". Podemos acentuar que diante da transculturação, processo pelo qual a cultura do dominado se faz presente com a do dominador, outros temas se interligam dando suporte também para a representação do resgate cultural. Quando na narrativa, a trama desenvolve situações onde o personagem, ao estar preso a uma recordação, se volta ao passado e vem ao presente trazendo à tona seus desejos, o resgate cultural tende a se concretizar via alegrias, saudades e decepções. Não seria esta a organização estrutural do conto "Hijo Solo"?

Sim, "Hijo Solo" (1972) é a história de Singu, o pequeno servente numa fazenda de nome "Lucas Huayk'o", que deseja manter e cuidar de um cachorro errante: "Singu buscaba un nombre. Recordaba febrilmente nombres de perros. 
--! Hijo Solo! - le dijo cariñosamente --." (ARGUEDAS: 1972, p. 62) No entanto, Singu sabe que "Lucas Huayk'o" é um inferno odioso: "? Cómo, por qué mandato 'Hijo Solo' había llegado hasta ese infierno odioso? ?Por qué no se había ido, de frente, por el puente, y había escapado de Lucas Huayk'o?" (ARGUEDAS: 1972, p. 64) E o menino continua: “-Gringo! !Aquí sufriremos! Pero no será de hambre - le dijo--. Comida hay, harto." (ARGUEDAS: 1972, p. 64) Por seu lado, "Hijo Solo" parecia compreender qual era a condição de seus donos: "? Sabía también que los doños de la hacienda, los que vivían en esta y en la outra banda se odiaban a muerte? ?Había oído las historias y rumores que corrían en los pueblos sobre los señores de 'Lucas Huayk'o'?" (ARGUEDAS: 1972, p. 66) Os "mistis" desse conto, Don Adalberto e Don Angel, dois irmãos "caínes", se enfrentam numa guerra sem trégua, uma maldição autodestrutiva ao invés de uma luta de interesses, onde a rivalidade se dá mais por monstruosidades, como arrasar colheitas, aniquilar animais e torturar quem quer que seja.

A estratégia escritural de Arguedas em "Hijo Solo" se evidencia quando um acontecimento simples, um encontro de dois excluídos ao acaso, dá início a um conjunto de transgressões monstruosas e violentas que podem ser lidas como um deslocamento de conteúdos, quais sejam: descrição de mundos antagônicos; ações sujeitas a uma ordem de motivações cerimoniais e culturais que estão enraizadas em tradições cujo veículo comunicacional é uma linguagem fragmentada, ocupada e por demais, tencionada; estruturas verbais "em trânsito" entre o espanhol e o Quéchua; expressões que manifestam claramente o entrecruzamento de uma oralidade quebrada, fragmentada interiormente, com a possibilidade de sua materialização na construção escritural arguediana. "Hijo Solo" parece ser o espaço onde todas essas tensões se dão a ver, onde o universo de sentido é uma luta pela representação, pela voz de todo um povo.

Seguindo o pensamento de Marcos Natali, teríamos o seguinte:

é verdade que boa parte da obra de Arguedas é de fato exatamente isto: a tentativa de inscrever o mundo andino em que o autor crescera, com sua língua, sua cultura e sua religiosidade, na forma da narrativa literária moderna... O que Rama escrevera sobre a transculturação de modo geral - que nela há uma busca da reconstrução daquilo que ele chama de "cosmovisão cultural"- certamente vale para o conto. Para o 
crítico uruguaio, essas obras instalam-se na intra-realidade latino-americana, cumprem a ingente tarefa de abarcar elementos contrários cujas energias buscam canalizar harmonicamente, resgatam o passado e apostam em um futuro que acelere a expansão da nova cultura, autêntica e integradora. (2005, p. 120)

Então, que expansão e integração, ou que tipo de transculturação estaria subscrevendo o conto "La Muerte de Los Arancos" (1972)? Em outros termos, quais marginais seriam, na realidade fictícia de "La Muerte de Los Arancos", o centro do mundo, o eixo de rotação em torno do qual nascem as histórias nas palavras de Vargas Llosa? O motivo que passa de conto em conto, estabelecendo um denominador comum, é a imagem de seres desterritorializados forçados a dar conta dos prejuízos sócio-econômicos e culturais causados pelo homem branco.

No conto "La Muerte de Los Arancos" será o sacristão Don Jáuregui quem precipita por um despenhadeiro o cavalo "tordillo", pertencente a um "misti", como esconjuro contra a peste. Uma leitura do conto através da chave da transculturação não estaria equivocada, já que o texto é, essencialmente, a transformação de uma cerimônia religiosa envolta de superstição e fragmentos lingüísticos em literatura. Vejamos o final do conto:

Don Jáuregui cantó en latín una especie de responso junto al 'trono' de la Virgen, luego se empinó y bajó el tapaojos, de la frente del tordillo, para cegarlo.

--! Fuera! - grito -- ! Adiós calavera! !Peste! ...

Vimos la sangre del caballo, cerca del trono de la Virgen, en el sitio en que se dio el primer golpe.

-- !Don Eloy, don Eloy! !Ahí está tu caballo! !Ha matado a la peste! En su propria calavera. !Santos, santos, santos! !El alma del tordillo recibid! !Nuestra alma es, salvada! !Adiós millahuay, despidillahuay...! (!Decidme adiós! !Despedidme...!)". (ARGUEDAS: 1972, p. 56-57)

E completa novamente o menino narrador: "Con las manos juntas estuvo orando un rato, el cantor, en latín, en quechua y en castellano." (ARGUEDAS: 1972, p. 57) A juventude do narrador não apaga a luz da razão humana e parece emprestar a ela (a razão) aspectos que apontam para um exercício bem sucedido de transculturação. Dentro do muro isolante da cultura opressora, o povo Quéchua, bastante arcaizado e se defendendo via dissimulação ou simulação de sincretismos de toda ordem, segue criando futuros, senão felizes, 
ao menos "extraños" em sua pluralidade lingüística e em sua multiculturalidade à distância.

"Orovilda" (1972), outro conto de Arguedas, nos fala de uma cidadela divorciada do mundo adulto onde colegas de escola (nosso pequeno narrador novamente ["alumno del primer año, un recién llegado de los Andes" (ARGUEDAS: 1972, p. 16)], Salcedo, Wilster e Gómez) se relacionam ora pela via da desconfiança ora pela hostilidade aberta e franca. "Orovilda", o conto, inicia em chave poética, de forma bastante "extraña" em sua religiosidade tangencial ["La víbora brota de una parte especial, negada, del polvo" (ARGUEDAS: 1972, p. 17)] e com o resumo do enredo escondido numa fábula:

El chaucato ve a la víbora y la denuncia; su voz se descompone. Cuando descubre a la serpiente venenosa lanza un silbido, más de alarma que de espanto, y otros chaucatos vuelan agitadamente hacia el sitio del descubrimiento, se posan cerca, miran el suelo con simulado espanto y llaman, saltando, alborotando. (ARGUEDAS: 1972, p. 15)

O eixo narrativo desse conto se dá também por meio de uma viagem; os meninos irão visitar uma lagoa encantada:

'Orovilca' significa en quechua 'gusano sagrado.' Es la laguna
más lejana de la ciudad; está en el desierto, tras una barrera de
dunas. Salcedo iba a bañarse a 'Orovilca' los días domingos
por la tarde, en la primavera. Yo lo acompañé algunas veces.
Ibamos por los caminos de chacra, porque entre la ciudad y
'Orovilca' no había carretera. (ARGUEDAS: 1972, p. 26)

No entanto, violência e morte fazem parte do conto e, como diz um dos personagens, "no debe $(m)$ venir únicamente de mis entrañas, sino de alguna otra necesidad antigua". (ARGUEDAS: 1972, p. 27) O final de "Orovilda" retoma a chave poética do início e conclui com um pássaro quase mítico que costuma habitar os fins-inícios-passados e indecidíveis futuros de Arguedas: "El mar, por el lado de 'Orovilca', es desierto, inútil; nadie quería buscar allí, donde solo los cóndores bajan a devorar piezas grandes. Los cóndores de la costa, vigilantes, casi familiares, despreciables." (ARGUEDAS: 1972, p. 43-44) Esses elementos diversos parecem indicar a originalidade da narrativa arguediana e, curiosamente, apontam para uma intimidade implacável com tantas culturas formadoras, onde a morte não é término e desaparecimento, nem expressão da fatal finitude humana. Ao contrário, a morte é instância de 
renovação e continuidade, de maneira também implacável, vinculada ao ritmo da vida cósmica. Há aí uma decomposição dos elementos desprezíveis que revela, de forma agitada e precisa, o local de des-cobrimento.

Último conto a ser aqui trabalhado, "El Barranco" (1972) narra o espanto e o desespero dos peões ao contar a Doña Grimalda que seu bezerro de nome Pringo caiu do barranco de K'ello-k'ello. Criatura "hermosa", Pringo parece encarnar numa realidade encantada de criação, uma criação que se dá de forma bem humorada, onde a cultura de resistência no cenário Andino se faz visível não somente em relação à tragédia, violência e morte, mas também à comédia, rito e encenação teatral:

La vaquera lo bautizó con ese nombre desde el primer día. 'El Pringo', porque era blanco entero. El Mayordomo queía llamarlo 'Misti', porque era el más fino y el más grande de todas las crías de su edad. - Parece extranjero - decía. ... y la gente del pueblo lo llamaron 'Pringo'. Es un nombre más cariñoso, más de indios, por eso quedó. (ARGUEDAS: 1972, p. 8-9)

A hibridização quase dicotômica de Pringo dá lugar à ritualização ou transculturação de seu corpo depois que o bezerro "cayó al barranco, rebotó varias veces entre los peñascos y llegó hasta el fondo del abismo." (ARGUEDAS: 1972, p. 7-8) Animal humanizado ou homem animalizado, Pringo parece encarnar uma força "extraña" da natureza, um mo(vi)mento estrangeiro numa rima quase tosca; um gringo que precisa despencar de um barranco, rodopiar várias vezes, até finalmente morrer para injetar a realidade (Andina) com uma vida iluminada de novo, de diferença, de uma fração complexa.

Tensões semelhantes podem ser encontradas em textos de outros escritores identificados como exemplos de um hibridismo cultural exitoso. À guisa de conclusão e no intuito de estender os pontos aqui trabalhados, de forma tentativa e como um prolegômeno, uma mirada inicial e por isso cambiante e pouco sistemática, vale lembrar que Arguedas "no se quedaba solo." Nossos olhos podem muito bem vislumbrar outros contos também "transculturadores", outros contos e autores que também e tão bem relataram a complexa fração Andina. "Taita Dios Nos Señala El Camino" e "El Despenador" de Francisco Vegas Seminario e "Los Gallinazos Sin Plumas" e "Mar Afuera" de Julio Ramon Ribeyro servem de exemplos de uma mirada estrábica, de ânimos exaltados, de uma fração complexa e de eixos de rotação indecidíveis no 
espaço híbrido e no tempo fragmentado do Peru Andino, indígena, espanhol e "misti", porque simultaneamente mistificado (como numa "hermosa" mentira) e mitificado (como num "extraño" mundo de sobre-naturais redenções).

\section{Referencias Bibliográficas}

ARGUEDAS, José María. Canciones quechuas. Américas. Washington: Unión Panamericana, Oct. 1957, n. 9. P. 33-34.

. Agua. In: Estuardo Núñez, Los Mejores Cuentos Peruanos (Tomo II). Peru: Latinoamericana, 1958. P. 15-43.

Primer Encuentro de Narradores Peruanos (Arequipa, 1965). Lima: Casa de la Cultura del Perú, 1969. P. 40-41.

El Forastero. In: José María Arguedas, El Forastero y Otros Cuentos. Uruguai: Sandino, 1972. P. 77-89.

Hijo Solo. In: José María Arguedas, El Forastero y Otros Cuentos. Uruguai: Sandino, 1972. P. 59-76.

. La Muerte de Los Arancos. In: José María Arguedas, El Forastero y Otros Cuentos. Uruguai: Sandino, 1972. P. 45-58.

. Orovilda. In: José María Arguedas, El Forastero y Otros Cuentos. Uruguai: Sandino, 1972. P. 13-44.

El Barranco. In: José María Arguedas, El Forastero y Otros Cuentos. Uruguai: Sandino, 1972. P. 5-12.

LLOSA, Mario Vargas. José María Arguedas, Entre Sapos y Halcones. Madrí: Ediciones Cultura Hispánica del Centro Iberoamericano de Cooperación, 1978.

NATALI, Marcos Piason. José María Arguedas aquém da literatura. Estudos Avançados, v. 19, n. 55, São Paulo, Sept/Dec 2005. P. 117-128.

ORTIZ, Fernando. El contrapunteo cubano del azúcar y del tabaco. Cuba: Editorial de ciencias sociales, La Habana , 1983.

RAMA, Ángel. Os processos de transculturação na narrativa latinoamericana. In: Ángel Rama, literatura e cultura na América Latina. São Paulo, EDUSP, 2001. 